\title{
An Analysis of the International Competitiveness of China's Tourism
}

\author{
HU Dongwan \\ Northeast Normal University \\ Changchun, China, 130000 \\ 329113471@qq.com.
}

\author{
SONG Yuxiang \\ Northeast Normal University \\ Changchun, China, 130000
}

\begin{abstract}
China's tourism resources are abundant and the development of tourism is wing-footed. It has been among the ranks of the world's tourism power nowadays. Based on the analysis of China's tourism data from 2008 to 2015, this paper adopts the international market share, trade competitive advantage index and revealed comparative advantage index to judge the tourism industry in china. It is found that China's overall competitiveness in tourism is in low-level. We should take effective measures to continuously nurture and enhance the international competitiveness of China's tourism industry, so that our country will certainly change from big country in tourism forward to the tourism power.
\end{abstract}

Keywords-Tourism industry; competitiveness; competition index; Revealed comparative advantage

\section{INTRODUCTION}

Tourism industry is a strong correlation industry. It takes important roles in stimulating economic growth and promoting international cultural exchanges. Lots of countries and regions are focusing on the development of tourism industry. China's tourism industry has made great achievements in rapid development in the past 30 years. Compared with developed countries, there are still exist high dependence on tourism resources, infrastructure construction backward, lack of tourism industry marketing capacity, related to support industry lag behind, industry system development is not perfect and so on. If scientifically analyzing China's tourism industry development of the internal powers mechanism and the impact of factors, in view of the problems to develop effective measures to enhance the competitiveness of the industry, we need in-depth systematic study. For industrial competitiveness and mechanism. Although in recent years, the competitiveness of China's tourism industry of the relevant research results is more extensive in research content. But from the contribution of tourism industry social aspects of China's tourism industry that study of the competitiveness is rare. It is the first time that the international competitiveness of China's tourism industry compared with that of the United States, Germany, France and Spain.

\section{DEVELOPMENT OF CHINA 'S TOURISM MARKET}

\section{A. The market of domestic tourism.}

Since the reform and opening up, with the continuous improvement of the per capita income level of our residents and the pursuit of a better spiritual and cultural life, the number of domestic tourists has increased year by year. In the national government and the relevant policies and regulations under the strong support of 2012, China's domestic tourism revenue has broken through two trillion Yuan mark for the first time. The number of domestic tourists in 2015 turned 3.3 times than in 2005 .The per capita domestic tourism spending has increased year by year, China's domestic tourism revenue generally showed a trend of increasing year by year. It can be seen that the tourism industry will play an increasingly important role in promoting the development of the nation's economy. The number of domestic tourists from2005 to 2015 is shown in Fig. 1.

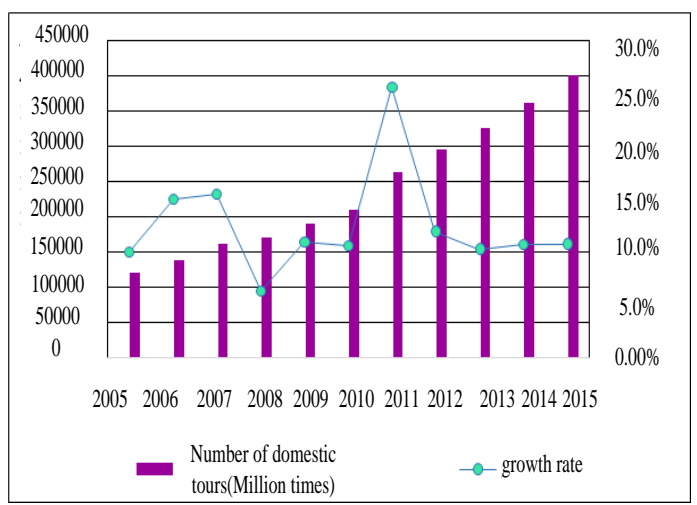

Fig. 1. China's domestic tourists from 2005 to 2015 in the number and growth rate.

As can be seen from the figure, the number of domestic tourists maintains the overall growth trend, but the growth rate is $6.34 \%$ in 2008 . This phenomenon is closely related with the international financial crisis and the Wenchuan earthquake. After 2009, the growth rate of domestic tourists remains above $10 \%$ and the domestic tourism market is in a period of rapid development.

As an important economic sector of the tertiary industry, domestic tourism income in the tertiary industry accounted for a large proportion of the total revenue. Domestic tourism income has an important role in the promotion of China's GDP growth. Domestic tourism revenue statistic has been shown from 2005 to 2015 in Fig. 2.

It can be seen from the Fig. 2 that domestic tourism revenue turned 6.5 times in the rapid development of domestic tourism industry. After 2010, the annual growth rate 
of domestic tourism revenue remained at $12 \%$ or above. ofIn 2011 domestic tourism revenue growth rate is $53.46 \%$, which is the fastest growth.

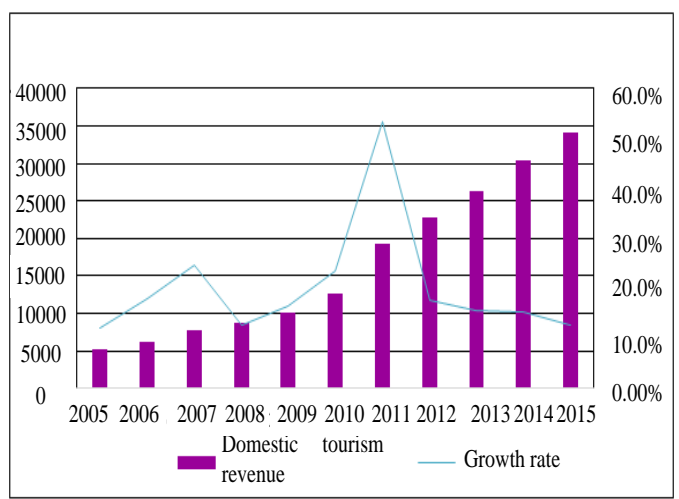

Fig. 2. China's domestic tourism revenue and growth rate from 2005 to 2015.

\section{B. Inbound tourism market.}

Because of China's long history, culture and the wide range of natural landscape attract tourists from all over the world. At this stage, China's tourism market scale is in the forefront of the world tourism market, In 2015, China received 134 million inbound tourists trips, turning into the world's fourth largest inbound tourism reception. From 2005 to 2015, the statistics of China's inbound tourists has been shown in Fig. 3.

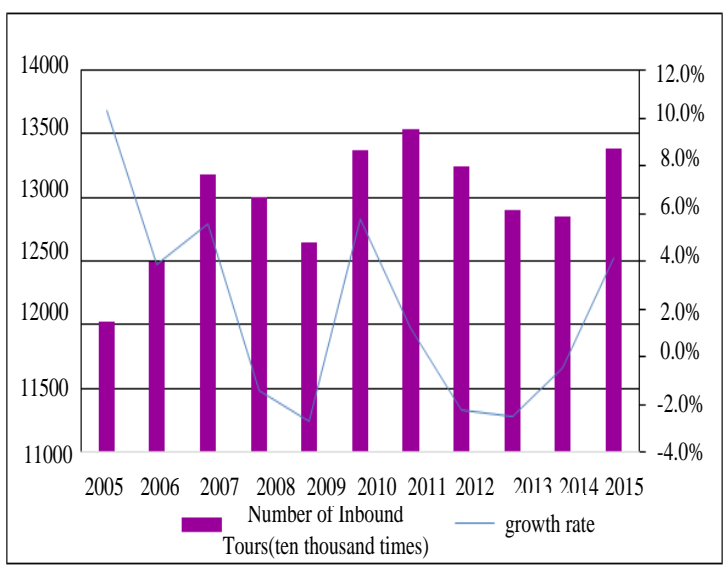

Fig. 3. the number of China's inbound tourists and growth rate from 2005 to 2015.

From Fig. 3 we can see that China's inbound tourism market is in a volatile state from 2005 to 2015 . Thanks to the international financial crisis , In 2009 China's inbound tourists growth rate is $2.73 \%$, which is in the first growth trough. But in 2010, China's inbound tourists bounced in the performance, which reflects the fast restore of the characteristics in tourism industry. In 2012 and 2013 China's inbound tourism market is the second growth trough, which is the global economic downturn. In the future, China's inbound tourism demand will continue to maintain a steady state and the Chinese government will also pursue visa-free or landing sign and other convenient policies to attract more inbound tourists, increasing the traditional culture of the Chinese nation in the international propaganda, grasping the "One Way All the Way" Strategy for China 's Tourism Market.

Although the number of inbound tourists in China is fluctuating, the foreign exchange income brought by China's inbound tourism is basically rising year by year. It can be seen that the per capita tourism consumption of inbound tourists is on the rise. In the period of steady tourism demand, it is an effective measure to improve the comprehensive economic benefits of tourism market. The foreign exchange income statistics of inbound tourism in China from 2005 to 2015 are shown in Fig. 4.

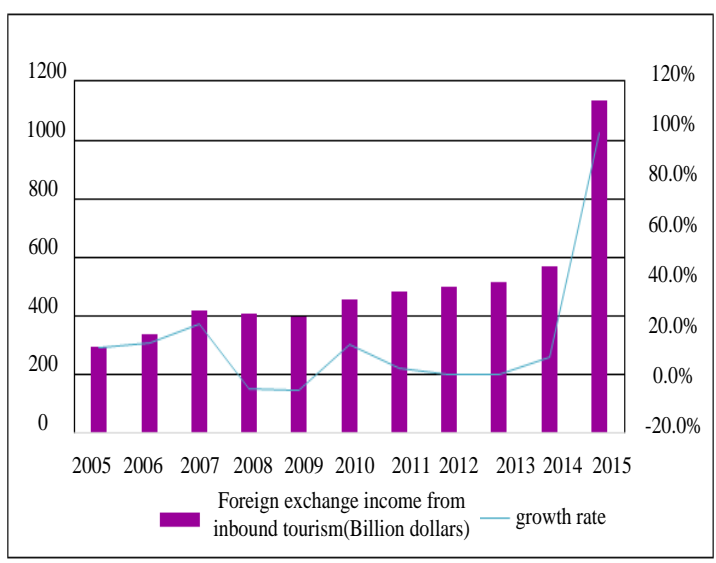

Fig. 4. China's foreign exchange income from inbound tourism and growth rate from 2005 to 2015 .

China's abundant tourism resources attract tourists from all over the world, more than half of the inbound tourists are from Asian countries, including South Korea, Japan and Malaysia. Europe is China's second largest tourist destination. China received a total of 4916.7 thousand European tourists in 2015. In 2015, the share of mainland tourists in China's inbound tourism market is shown in Fig. 5.

\section{A COMPARATIVE ANALYSIS OF THE COMPETITIVENESS OF CHINA 'S TOURISM INDUSTRY}

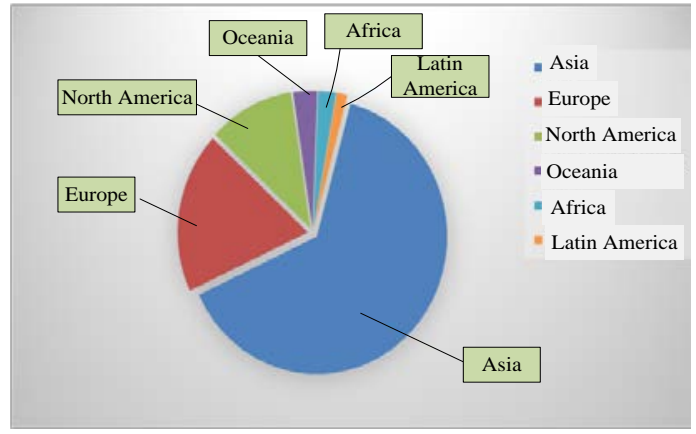

Fig. 5. China's inbound tourism market share in 2015.

Tourism industry international competitiveness refers to a country's tourism industry compared to other countries profitability, if the competitiveness is stronger, the tourism products and services provided by the market is more in line with the needs. The international competitiveness of the tourism industry is mainly reflected through the international 
market share, trade competitive advantage index and comparative advantage index.

\section{A. International market share international comparison.}

International market share refers that a country's products or industry exports accounted for the world's exports of the product or industry. The increase or decrease in the value of a country's products or industries in the world market mean to enhance or weaken the competitive strength.

Using the formula to calculate the competitiveness of China and the world's tourism industry ranked fourth in Spain, France, Germany, the United States the international market share, the results are shown in Table 1.

TABLE I. COMPARISON OF THE INTERNATIONAL MARKET SHARE OF THE FIVE COUNTRIES

\begin{tabular}{llllcl}
\hline years & Spain & France & Germany & USA & China \\
\hline 2008 & 0.0639 & 0.0588 & 0.0415 & 0.1455 & 0.0427 \\
2009 & 0.0608 & 0.0564 & 0.0394 & 0.1413 & 0.0455 \\
2010 & 0.0554 & 0.0498 & 0.0367 & 0.1409 & 0.0481 \\
2011 & 0.0565 & 0.0515 & 0.0365 & 0.1396 & 0.0458 \\
2012 & 0.0508 & 0.0489 & 0.0348 & 0.1465 & 0.0456 \\
2013 & 0.0518 & 0.0492 & 0.0349 & 0.1460 & 0.0459 \\
2014 & 0.0510 & 0.0511 & 0.0357 & 0.1467 & 0.0461 \\
\hline \multicolumn{5}{c}{ Source: Calculated based on UNCTAD database }
\end{tabular}

In order to more intuitive comparison of the five countries of the market share, the table will be converted into a line chart, as shown in Fig. 6.

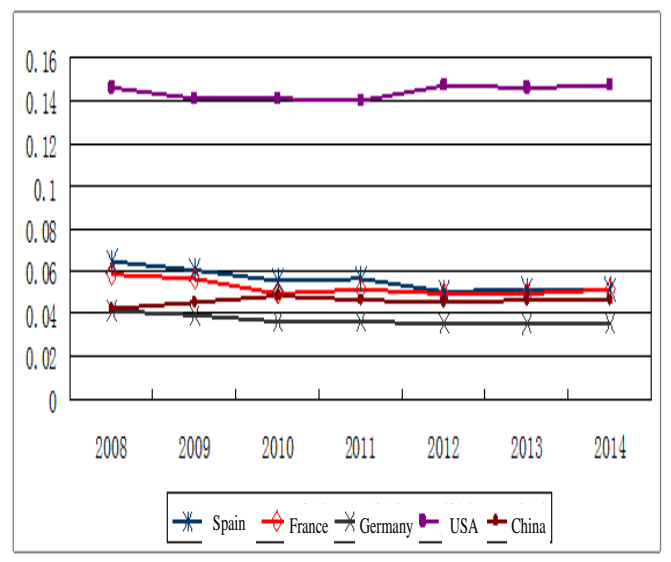

Fig. 6. The international market share of the five countries.

It can be seen from the Fig. 6, Spain, France and Germany which the three countries are as the tourism industry competitiveness of the top three countries and the market share is in a slight fluctuation in the state. The average market share of Spain and France are about 5\%. The average market share of Germany is about $3.7 \%$. In the future, its market share will remain steady increase, which it is related to good social atmosphere; perfect the infrastructure, the importance of the tourism industry and the development of the EU countries. US international market share remained at around $14 \%$, occupying an absolute advantage. In recent years, China's market share increased year by year, but it is difficult to surpass the United States as the world's largest exporter of tourism services in a short time.

\section{B. International Comparison of Trade Competitive Advantage Index.}

The competitive advantage index (TC index) is an important tool to analyze the competitiveness of the industry, and the import and export are taken into account in the formula of the index.

TC index is in the range of -1 to 1 . The performance is stronger when the TC index for the value of is closer to 1 . On the contrary, the value is smaller when the competitiveness is weak. The advantage of applying the trade competitive advantage index to the competitiveness of the tourism industry can exert the advantages of influencing factors such as inflation and national size, and can compare the differences of the competitiveness of the tourism industry between different countries. The formula of comparing the TC index of the five countries to determine the advantages of its tourism trade is shown in Table 2.

TABLE II. COMPARISON OF TC INDEX OF TOURISM TRADE IN FIVE COUNTRIES.

\begin{tabular}{ccclcc}
\hline years & Spain & France & Germany & USA & China \\
\hline 2008 & 0.5036 & 0.1588 & 0.0873 & 0.2302 & 0.0608 \\
2009 & 0.5178 & 0.1270 & 0.0731 & 0.2064 & -0.0421 \\
2010 & 0.5187 & 0.0959 & 0.0694 & 0.2331 & -0.0893 \\
2011 & 0.5543 & 0.0989 & 0.0862 & 0.2626 & -0.1763 \\
2012 & 0.5620 & 0.1223 & 0.0934 & 0.2671 & -0.3097 \\
2013 & 0.5701 & 0.1345 & 0.1064 & 0.2723 & -0.2761 \\
2014 & 0.5723 & 0.1563 & 0.1121 & 0.2843 & -0.2473 \\
\hline
\end{tabular}

In order to more intuitive comparison of the five countries competitive advantage, the table is converted into a line chart, as shown in Fig. 7.

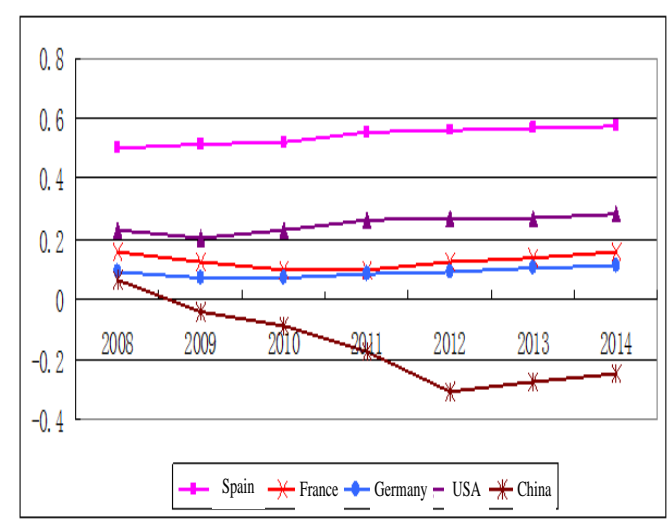

Fig. 7. TC index line chart in five countries.

From Fig. 7 we can see that the other four countries are positive in the TC index apart from China, which Spain's TC index is closest to 1 . We can see that Spain is the strongest countries in the tourism trade competitive advantage among these countries. The future was dominant Growth trend, followed by the United States. The two countries can be called a strong competitive advantage country. France and Germany, the level of similar advantages, the tourism industry in the financial crisis after a brief competitive advantage decline, but soon returned quickly. The two countries can be called a tourist country with a weak competitive advantage. 
China's tourism trade is clearly at a disadvantage, in a large gap with the other four countries.

\section{Comparison of Revealed Comparative Advantage.}

Revealed Comparative Advantage is proposed by Barasa to determine a country in a particular industry in the international market, the relative advantages, and then vigorously develop the industry to obtain more competitive.

$$
R A C i n d e x=(X i / X t) /(X w / X t w)
$$

Xt refers that the total exports of tourism products in a coutry. Xt refers that the world's total exports of tourism products. Xw refers the world's exports of all products in the world; Xtw refers the total exports of tourism products. RAC index can eliminate the other countries in the world of tourism products export fluctuations affect the country's tourism industry RAC index results. The greater the value of RAC indicates that the competitiveness of the country's tourism industry is stronger. On the contrary, RAC value smaller indicates the weaker competitiveness of the tourism industry in the country. RAC numerical range corresponding to the competitiveness of the strength of the summary is shown in Table 3.

TABLE III. RAC NUMERICAL INTERVAL DIVISION.

\begin{tabular}{|c|c|c|c|c|}
\hline Range of RAC & $\mathbf{R A C}<0.8$ & $0.8 \leq R A C \leq 1.25$ & $1.25 \leq R A C \leq 2.5$ & RAC $>2.5$ \\
\hline $\begin{array}{l}\text { Comparison of } \\
\text { competitiveness }\end{array}$ & Weak & Moderate & Strong & Very strong \\
\hline
\end{tabular}

Using the above formula to calculate the RAC index results of the five countries is shown in Table 4.

TABLE IV. COMPARISON OF FIVE COUNTRIES RAC INDEX.

\begin{tabular}{cccccc}
\hline years & Spain & France & Germany & USA & China \\
\hline 2008 & 2.9825 & 1.5194 & 0.9702 & 1.5665 & 0.5341 \\
2009 & 2.7297 & 1.3278 & 0.9398 & 1.4231 & 0.5441 \\
2010 & 2.6986 & 1.3024 & 0.9367 & 1.4564 & 0.5248 \\
2011 & 2.6027 & 1.4014 & 0.9409 & 1.4773 & 0.4934 \\
2012 & 2.6541 & 1.4189 & 0.9431 & 1.4831 & 0.4672 \\
2013 & 2.6701 & 1.4221 & 0.9489 & 1.4984 & 0.4581 \\
2014 & 2.6824 & 1.4367 & 0.9510 & 1.5143 & 0.4945 \\
\hline & & & Source: Calculated based on UNCTAD database
\end{tabular}

In order to intuitive comparison of the five countries in the RAC, the table will be converted into a line chart. We can see that Spain's RAC index is more than 2.5 and its tourism industry competitiveness is very strong. The competitive ability of United States is slightly stronger than France, which is a highly competitive country.

Germany is a country with moderate competitiveness. China tourism industry RAC index has been less than 0.8 , in a weak state. The comparison shows that China's tourism industry in the same competition with the tourism power is still at a disadvantage. Therefore, it is very urgent to enhance China's industrial competitiveness, which is related to China's tourism industry's long-term sustainable development.

\section{CONCLUSION}

The tourism industry in China are still at a disadvantage in the competition with the state power in tourism, the international competitiveness of China's tourism industry, there is still much space for improvement, and effective measures should be taken to continuously cultivate and enhance the international competitiveness of China's tourism industry, to make our country translate from a big tourism country to a great tourism power.

\section{REFERENCES}

[1] Yin, H, Research on Evaluation System of Venture Capital Project Based on High-tech Achievement Transformation, Harbin Engineering University, Heilongjiang, China,2007.

[2] Yin, H, China's open-end fund portfolio research, Harbin Engineering University, Heilongjiang, China,2005.

[3] Zhang, X.H, China's tourism industry international competitiveness research, Harbin Engineering University, Heilongjiang, China,2009. 